4. Felice M. S., Gallego M. S., Alonso C. N. (2011). "Prognostic impact of $\mathrm{t}(1 ; 19) /$ TCF3-PBX1 in childhood acute lymphoblastic leukemia in the context of Berlin-Frankfurt-Münster-based protocols". Leuk Lymphoma, 52 (7), pp. 1215-21.

5. Hu Yixin, He Hailong, Lu Jun (2016). "E2APBX1 exhibited a promising prognosis in pediatric acute lymphoblastic leukemia treated with the CCLG-ALL2008 protocol". OncoTargets and therapy, 9, pp. 7219-7225.

6. Hunger S. $P_{.}$, Lu $X .$, Devidas M. (2012). "Improved survival for children and adolescents with acute lymphoblastic leukemia between 1990 and 2005: a report from the children's oncology group". J Clin Oncol, 30 (14), pp. 1663-9.

7. Uckun F. M., Sensel M. G., Sather H. N. (1998). "Clinical significance of translocation $t(1 ; 19)$ in childhood acute lymphoblastic leukemia in the context of contemporary therapies: a report from the Children's Cancer Group". J Clin Oncol, 16 (2), pp. 527-35.

8. Kiyokawa Nobutaka, Iijima Kazutoshi, Tomita Osamu (2014). "Significance of CD66c expression in childhood acute lymphoblastic leukemia". Leukemia research, 38 (1), pp. 42-48.

\title{
ĐẶC ĐIỂM CỦA BỆNH NHÂN ĐA U TỦY CÓ KHUẾCH ĐẠI 1q21 TẠI BỆNH VIỆN TRUYỀN MÁU HUYẾT HỌC
}

\section{TÓM TẮT}

Mục tiêu: Mô tả đặc điểm lâm sàng, xét nghiệm lúc chẩn đoán và đặc điểm di truyền của bệnh nhân đa u tủy có khuếch đại NST 1q. Phương pháp nghiên cứu: Nghiên cứu hồi cứu cắt ngang mô tả hàng loạt ca. Đối tượng: 95 bệnh nhân đa u tủy mới chẩn đoán tại bệnh viện truyền máu huyết học thỏa tiêu chuẩn chọn mấu trong khoảng thời gian từ $1 / 2017$ đến 12/2020. Kết quả và bàn luận: Tỉ lệ bệnh nhân mang khuếch đại NST 1q là 29,5\% ( $\mathrm{n}=$ 28). Trong số các bất thường về lâm sàng, triệu chứng thiếu máu và đau nhức xương thường gặp nhất (> 70\%), ngoài ra còn có triệu chứng u tương bào, sụt cân, sốt, xuất huyết, không có sự khác biệt giữa 2 nhóm có và không có khuếch đai î̀. Tăng calci máu, tăng Beta-2-microglobulin, giai đoạn bệnh muộn, nhiều bất thường di truyền và bất thường thuộc nhóm nguy cơ cao là những đặc điểm khác biệt đáng kể giữa 2 nhóm nghiên cứu ( $\mathrm{p}<0.05)$. Kết luâan: Có sư khác biệt về các đặc điểm sinh học của nhóm bệnh nhân có khuếch đại NST $1 \mathrm{q}$, cho thấy nhóm BN nay thuộc nhóm nguy cơ cao.

Tư khóa: khuếch đại 1q21, đa u tủy, FISH, bất thường nhiễm sắc thể.

\section{SUMMARY \\ CHARACTERISTICS OF MULTIPLE MYELOMA PATIENTS WITH GAIN CHROMOSOME 1q AT BLOOD TRANSFUSION AND HEMATOLOGY HOSPITAL}

${ }^{1}$ Bênh viện Truyền máu Huyết hơc.

${ }^{2}$ Đại học Y Dược Thành phố Hồ Chí Minh.

${ }^{3}$ Đai hoc Y Khoa Pham Ngoc Thach, TP. Hồ Chí Minh. Chịu trách nhiệm chính: Phan Thị Xinh

Email: phanthixinh73@gmail.com

Ngày nhận bài: 1.6 .2021

Ngày phản biên khoa hoc: 2.8.2021

Ngày duyệt bài: 9.8.2021
Trần Thùy Anh ${ }^{1,2}$, Phạm Kim Thạnh ${ }^{2}$, Nguyễn Tấn Bỉnh ${ }^{3}$, Phan Thị Xinh ${ }^{1,2}$

Objectives: describe characteristics of clinical symptoms, laboratory values at diagnosis and genetic features in multiple myeloma patients with amplification of chromosome 1q. Methods: crosssectional descriptive studies are retrospective. Subjects: 95 patients newly diagnosed with multiple myeloma were included in this study at Blood transfusion hematology hospital from January 2017 to December 2020. Results: the frequency of patients with chromosome 1q amplification was $29,5 \%$ ( $n=$ 28). Among the clinical abnormalities, anemia and bone pain were the most common $(>70 \%)$. There were no difference between patients with and without 1q amplification in plasmacytoma, weight loss, fever and hemorrhage. However, hypercalcaemia, Beta-2microglobulin level, late stage of disease, multiple chromosomal abnormalities and high-risk genetic abnormalities were significant difference between 2 groups $(p<0.05)$. Conclusion: There are differences in the biological characteristics of the patients with chromosome 1q amplification, indicating that this group of patients belongs to the high-risk group.

Key words: 1q21 amplification, multiple myeloma, FISH, chromosome abnormalities.

\section{I. ĐẶT VẤN ĐỀ}

Đa u tủy là bệnh tân sinh ác tính của tương bào ở tủy xương và một số cơ quan khác, phổ biến thứ hai trong các bệnh lí ác tính huyết học và đặc trưng bởi tính không đồng nhất về mặt lâm sàng cũng như kết cục của bệnh nhân. Hiện nay, việc điều trị đa u tủy đã được cải thiện đáng kể, đó là nhờ sự ra đời của các thuốc mới như thuốc ức chế proteasome, thuốc điều hòa miễn dịch, kháng thể đơn dòng.... Tuy nhiên, đa u tủy là bệnh lí đáp ứng điều trị, nhưng sau đó sẽ tái phát, dù là ở nhóm bệnh nhân đạt được đáp ứng hoàn toàn (complete response - CR) ban đâu. Có nhiều yếu tố tiên lượng bệnh như nồng độ $\beta 2$ - 
microglobulin, số lượng tương bào trong tủy xương, di truyền tế bào, và các bất thường gen khác.... Một trong những yếu tố quan trọng nhất để tiên lượng cho bệnh nhân đa u tủy là dựa trên các bất thường di truyền được xác định bằng xét nghiệm nhiễm sắc thể đồ và/hoặc lai tại chỗ phát huỳnh quang (FISH). Khuếch đại nhiễm sắc thể $1 q$ là một trong những bất thường di truyền phổ biến nhất được ghi nhận ở bệnh nhân đa u tủy, chiếm khoảng $40 \%$ [6]. Tuy nhiên, giá trị tiên lưỡng của khuếch đại 1q ở bệnh nhân đa u tủy vẫn còn đang tranh cãi. Vậy câu hỏi đặt ra là có sự khác biệt về đặc điểm sinh học giữa nhóm bệnh nhân có khuếch đại $1 \mathrm{q}$ so với nhóm không có khuếch đại không? Vì vậy, chúng tôi thực hiện khảo sát đặc điểm sinh học ở nhóm bệnh nhân đa u tủy có khuếch đại 1q tại bệnh viện Truyền máu Huyết học.

\section{II. ĐỐI TƯợNG VÀ PHƯƠNG PHÁP NGHIÊN CỨU}

\section{1. Đối tượng nghiên cứu:}

2.1.1. Dân số nghiên cứu: bệnh nhân mắc bệnh đa u tủy mới chẩn đoán tại Bệnh viện Truyên máu Huyết học từ tháng 01/2017 đến tháng 12/2020.

\subsubsection{Tiêu chuẩn lựa chọn bệnh nhân:}

- Tiêu chuẩn nhận vào: thỏa mãn tất cả các tiêu chuẩn sau:

- Bệnh nhân được chẩn đoán xác định đa u tủy thỏa tiêu chuẩn của IMWG.

- Bệnh mới chẩn đoán và chưa được điều trị trước đó.

- Có làm đủ các xét nghiêm FISH để tìm $\mathrm{t}(4 ; 14)$, del17p, del13q và nhiếm sắc thể đồ lúc chẩn đoán.

- Tiêu chuẩn loại trừ: ít nhất một trong các tiêu chuẩn sau

- Bệnh nhân không làm đủ các xét nghiệm lúc chẩn đoán, bao gồm: huyết học, sinh hóa và di truyền tế bào.

- Hồ sơ bệnh án không đầy đủ.

\subsection{Phương pháp nghiên cứu:}

Thiêt kế nghiên cứu: mô tả cắt ngang, hồi cứu. Cõ̃ mẫu nghiên cứu: $n=93$, được ước tính theo tỉ lệ bệnh nhân đa u tủy mới chẩn đoán có khuếch đại 1q21 là 40\% từ các nghiên cứu trên thế giới [6].

Kर̃ thuật sử dụng: kỹ thuật FISH và kính hiển vi điện tử, sử dụng probe đặc hiệu là $\mathrm{t}(1 ; 19)(q 23 ; p 13)$ của Cytocell để phát hiện khuếch đại NST 1q, phân tích 200 tế bào để phát hiện khuểch đại NST 1q.

Xử IV́ số liệu: dữ liệu được ghi nhận vào phiếu thu thập số liệu (bao gồm: tuổi, giới, các xét nghiệm sinh hóa và di truyền tế bào), tổng hợp và phân tích trên phần mềm Microsoft Excel và phần mềm Stata phiên bản 14.0, sử dụng phép kiểm $t$ để so sánh hai trung bình và phép kiểm chi bình phương để so sánh hai tỉ lệ.

\section{KẾT QUẢ NGHIÊN CỨU}

Đặc điểm chung của nhóm bệnh nhân nghiển cứu:

Đăc điểm dịch tễ: từ tháng 02/2021 đến tháng 07/2021, chúng tôi đã thu thập được 95 bệnh nhân thỏa tiêu chuẩn chọn mẫu. Tuổi trung bình lúc chẩn đoán trong nghiên cứu là 57 tuổi (giới hạn $35-81$ tuổi). Có bệnh 41 nhân nam và 54 bệnh nhân nữ, chiếm tî lệ lần lượt là $43,2 \%$ và $56,8 \%$.

Đặc điểm lâm sàng: Triệu chứng lâm sàng thường gặp là thiếu máu và đau xương như biểu đồ 1.

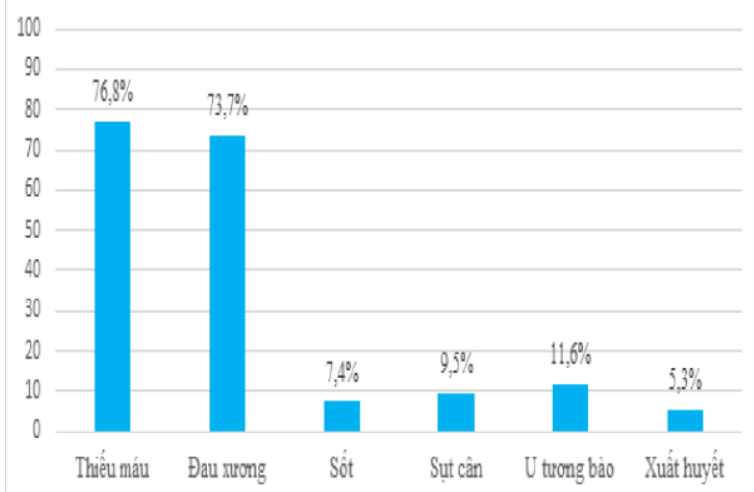

Biểu đồ 1. Các triệu chứng lâm sàng lúc nhập viện

Tỉ lệ khuếch đại 1q23 ở bệnh nhân đa u tủy mới chẩn đoán: Trong 95 bệnh nhân được khảo sát khuếch đại NST 1q bằng kỹ thuật FISH sử dụng đoạn dò lai hóa ở vị trí 1q23, chúng tôi phát hiện 28 bệnh nhân có khuếch đại NST 1q, chiếm tỳ lệ 29,5\%.

So sánh đặc điểm giữa bệnh nhân có và không có khuếch đại NST1q: Hầu hết bệnh nhân có tình trạng thiếu máu (dựa vào chỉ số $\mathrm{Hb}$ ) lúc chẩn đoán, số lượng tiểu cầu và bạch cầu đa nhân trung tính trong giới hạn bình thường, không có sự khác biệt về các chỉ số máu giữa nhóm có và không có khuếch đại NST 1q. Các đăc điểm khác như tổn thương xương lúc chẩn đoán, giảm albumin máu, tăng LDH máu, đa số tiết IgG, có sự tương đồng giữa 2 nhóm nghiên cứu. Tuy nhiên có sự khác biệt giữa 2 nhóm về chỉ số canxi ion hóa, mức protein, B2M, chỉ số ISS và các bất thường NST như Bảng 1. 
Bảng 1. Đặc điểm sinh học của hai nhóm có và không có khuếch đại NST 1q

\begin{tabular}{|c|c|c|c|c|}
\hline Thông số & $\begin{array}{c}\text { Tất cả BN } \\
(\mathrm{n}=95) \\
\mathrm{n}(\%)\end{array}$ & $\begin{array}{c}\text { Có khuếch đại 1q } \\
(n=28) \\
n(\%)\end{array}$ & $\begin{array}{l}\text { Khống khuếch } \\
\text { đại } 1 q(n=67) \\
n(\%)\end{array}$ & $\underset{\text { p }}{\text { Giá trị }}$ \\
\hline $\begin{array}{l}\text { Tuối trung bình (năm) } \\
\text { (Phạm vi) }\end{array}$ & $\begin{array}{c}57 \\
(35-81)\end{array}$ & $\begin{array}{c}57 \\
(35-81)\end{array}$ & $\begin{array}{c}57 \\
(35-78)\end{array}$ & 0.883 \\
\hline Nam/nũ & $\begin{array}{c}41 / 54 \\
(43,2 / 56,8)\end{array}$ & $\begin{array}{c}12 / 16 \\
(42,9 / 57,1)\end{array}$ & $\begin{array}{c}29 / 38 \\
(43,3 / 56,7)\end{array}$ & 0.969 \\
\hline Creatinin > $177(\mu \mathrm{mol} / \mathrm{L})$ & $12(12,6)$ & $6(2,4)$ & $6(9)$ & 0.095 \\
\hline Canxi ion hóa > 1,3 (mmol/L) & $19(20)$ & $10(35,7)$ & $9(13,4)$ & 0.013 \\
\hline Tốn thương xương trền Xquang & $90(94,7)$ & $27(96,4)$ & $63(94)$ & 0.633 \\
\hline Albumin $<35 \mathrm{~g} / \mathrm{L}$ & $59(62,1)$ & $19(67,9)$ & $40(59,7)$ & 0.455 \\
\hline Protein $>100 \mathrm{~g} / \mathrm{L}$ & $36(37,9)$ & $16(57)$ & $20(30)$ & 0.012 \\
\hline $\mathrm{B} 2 \mathrm{M}>5,5 \mathrm{mg} / \mathrm{L}$ & $42(44,2)$ & $17(60,7)$ & $25(37,3)$ & 0.036 \\
\hline ISS (I-II/III) & $52(54,7)$ & $10 / 18(35,7 / 64,3)$ & $42 / 25(62,7 / 37,3)$ & 0.016 \\
\hline $\mathrm{t}(4 ; 14)$ & $19(20)$ & $10(35,7)$ & $9(13,4)$ & 0.013 \\
\hline del17p & $11(11,6)$ & $6(21,4)$ & $5(7,5)$ & 0.052 \\
\hline del13q & $27(28,4)$ & $12(42,9)$ & $15(22,4)$ & 0.044 \\
\hline NST đồ bất thường & $32(33,7)$ & $15(53,6)$ & $17(25,4)$ & 0.008 \\
\hline
\end{tabular}

\section{BÀN LUẬN}

Trong 4 năm có 95 bệnh nhân thỏa tiêu chuẩn được đưa vào nghiên cứu. Tuổi trung bình của bệnh nhân trong nghiên cứu là 57 tuổi. Tỉ lệ nam/nữ là $0,76 / 1$. Phần lớn bệnh nhân có triệu chứng thiếu máu $(76,8 \%)$ và đau nhức xương $(73,7 \%)$, những triệu chứng này cũng được ghi nhận trong nghiên cứu của tác giả Robert A Kyle [7]. Đôi khi bệnh nhân biểu hiện sụt cân, xuất huyết và nhiễm trùng. Ngoài ra, nghiên cứu ghi nhận 11 trường hợp có $u$ tương bào ngoài tủy chiếm $11,6 \%$, tương tự nghiên cứu của tác giả Bladé và cộng sự [2].

Tỉ lệ bệnh nhân đa u tủy mới chẩn đoán mang khuếch đại NST 1q trong nghiên cứu của chúng tôi là $29,5 \%$, thấp hơn so với kết quả các nghiên cứu khác như của tác giả $\mathrm{S}$ Fabris là $45 \%$, tác giả Chen $D$ và cộng sự là $46,03 \%$ [3] [1]. Có rất nhiều gen nằm trên nhánh dài nhiếm sắc thể $1 q$, đặc biệt là vùng $1 q 21.1$ - q23.3, một số gen được nghiên cứu như CKS1B thuộc họ Cks/Suc1 là một protein nhỏ liên kết với các protein kinase phụ thuộc cyclin, hay PSMD4 là một trong những gen liên quan đến giảm đáp ứng với bortezomib, ngoài ra còn các gen khác như MUC1, MCL1, PDZK1， IL6R và BCL9 cũng nằm trên vùng này [6]. Sự biểu hiện bất thường của các gen này liên quan đến việc kháng thuốc cũng như thúc đẩy tăng sinh và xâm nhập của các tương bào ác tính trong bệnh đa u tủy, do đó, mang ý nghĩa tiên lượng xấu.

Từ kết quả của nghiên cứu, chúng tôi ghi nhận những khác biệt quan trọng về đặc điểm sinh học giữa nhóm bệnh nhân có và không có khuếch đại 1q. Những bệnh nhân mang khuếch đại 1q có: tăng calci máu và suy thận nhiều hơn (lần lượt là $35,7 \%$ vs $13,4 \%, 21,4 \%$ vs $9 \%$ ), tăng B2M cao hơn $(60,7 \%$ vs $37,3 \%, p=0.036)$, tăng tỉ lệ tiết IgA $(21,4 \%$ vs $12 \%)$, giai đoạn bệnh theo ISS cao hơn (giai đoạn III chiếm $64.3 \%$ vs $37.3 \%, p=0.016)$, bất thường $\mathrm{di}$ truyền đi kèm nhiêu hơn ( $53,6 \%$ vs $25,4 \%, p=$ 0.008 ), tất cả đều liên quan đến kết cục xâu cho bệnh nhân đa u tủy [5] [8]. Trong một phân tích đa biến, nồng độ $B 2 M$ huyết thanh và giai đoạn bệnh là những yếu tố tiên lượng độc lập quan trọng về sông còn [8]. Suy thận cũng khá phồ biến ở bệnh nhân đa u tủy, từ $20-60 \%$ trường hợp theo các nghiên cứu trên thế giới [7]. Có hai nguyên nhân chính gây suy thận: bệnh thận do trụ đa u tủy (hay còn gọi là bệnh thận do trụ chuỗi nhẹ) và tăng calci máu. Điểu này cũng phù hợp với nghiên cứu của chúng tôi, tỉ lệ bệnh nhân tăng calci máu cao hơn 2,5 lần ở nhóm có với không có khuếch đại 1q. Theo hệ thống phân Ioại R-ISS, các bất thường di truyền thuộc nhóm nguy cơ cao dựa trên kỹ thuật FISH bao gồm: $\mathrm{t}(4 ; 14)$, del17p, và $\mathrm{t}(14 ; 16)$, trong đó $\mathrm{t}(4 ; 14)$ là chuyển vị nhiếm sắc thể phổ biến thứ hai sau $\mathrm{t}(11 ; 14)$, chiếm khoảng $15 \%$ các trường hợp, thường xuất hiện cùng với bất thường nhiểm sắc thể 13 (monosomy 13 hoăc del13q), được xác định là có tiên lượng xấu [4]. Kết quả của nghiên cứu cho thây $B N$ có khuếch đại $1 q$ thường có tì lệ cao đi kèm $t(4 ; 14)$, del13q và del17p. Trong đó, tỉ lệ bất thường nhiễm sắc thể đi kèm cao hơn ở nhóm có khuếch đại $1 \mathrm{q}(\mathrm{p}=0.008)$. Gợi ý rằng nhóm bệnh nhân có khuếch đại $1 \mathrm{q}$ thường đi kèm các đặc điểm nguy cơ cao có thể dẫn đến kết cục xấu hơn [4]. Tuy nhiên, số lượng bệnh 
nhân thu thâp còn ít, bước đầu so sánh các đặc điểm sinh học và nhận thấy một số khác biệt có ý nghĩa, chưa đánh giá kết quả điều trị cũng như theo dôi thời gian sống còn của bệnh nhân trước khi kết luận nhóm có khuếch đại 1q là xấu so với nhóm không có khuếch đại 1q.

\section{KẾT LUÂ̂N}

Trong nghiên cứu này, chúng tôi đã mô tả các đặc điểm lâm sàng và cận lâm sàng của bệnh nhân đa u tủy mới chẩn đoán có khuếch đại NST 1q, và cho thây có sự khác biệt so với nhóm không có khuếch đại NST' 1q.

\section{TÀI LIÊU THAM KHẢO}

1. Chen D., Zhou D., Xu J., et al. (2019), "Prognostic Value of 1q21 Gain in Multiple Myeloma", Clin Lymphoma Myeloma Leuk, 19 (3), pp. e159-e164.

2. Bladé J., de Larrea C. F., Rosiñol L. (2012), "Extramedullary involvement in multiple myeloma", Haematologica, 97 (11), pp. 1618.
3. Fabris S., Ronchetti D., Agnelli L., et al. (2007), "Transcriptional features of multiple myeloma patients with chromosome 1q gain", Leukemia, 21 (5), pp. 1113-1116.

4. Grzasko N., Hajek R., Hus M., et al. (2017), "Chromosome 1 amplification has similar prognostic value to del $(17 \mathrm{p} 13)$ and $\mathrm{t}(4 ; 14)(\mathrm{p} 16$; q32) in multiple myeloma patients: analysis of reallife data from the Polish Myeloma Study Group", Leukemia \& lymphoma, 58 (9), pp. 2089-2100.

5. Karim K. J., Hassan A. M., Getta H. A., et al. (2020), "Frequency and prognostic significance of hypercalcemia in patients with multiple myeloma", Medical Journal of Babylon, 17 (4), pp. 327.

6. Kenneth Kaushansky M., MACP, Marshall A. Lichtman M., Josef T. Prchal $M_{\text {., }}$ et al. (2016), "Williams Hematology 9th", Part XI (107), pp. 1733 - 1747.

7. Kyle R. A., Gertz M. A., Witzig T. E., et al., "Review of 1027 patients with newly diagnosed multiple myeloma". in Mayo Clinic Proceedings. 2003. Elsevier.

8. Rossi D., Fangazio M., De Paoli $L_{\text {., }}$ et al. (2010), "Beta-2-microglobulin is an independent predictor of progression in asymptomatic multiple myeloma", Cancer, 116 (9), pp. 2188-2200.

\section{ĐẶC ĐIỂM XƯƠNG HÀM DƯỚI TRÊN PHIM SỌ NGHIÊNG TELE TỪ XA (CEPHALOMETRICS) Ở BÊ̂NH NHÂN SAI LỆCH XƯƠNG LOẠI III}

\section{TÓM TẮT}

Sai lệch xương loại III được coi là môt rối loạn phức hợp so - mặt phức tạp, có thể là biểu hiện sứ nhô ra của hàm dưới hoặc hàm trên lùi sau hoặc kết hợp cả hai. Sự hiểu biết về đăc điểm tăng trưởng so mặt, đặc biệt cấu trúc xương hàm dưới ở nhóm bệnh nhân này sẽ giúp bác sĩ xác đinh được thời gian và cơ học điều trị. Nghiên cứu nhẳm mục đích mô tả đặc điểm xương hàm dưới trên phim Cephalometrics ở bệnh nhân sai lệch xương loại III tại Viện Đào tạo Rằng Hàm Măt - Trường Đai họ Y Hà Nội. Phim so nghiêng từ xa trước điều trị của 70 bệnh nhân từ 18 tuổi trở lên, không có tiền sử chấn thương hoặc dị tật vùng hàm mặt, được đo đạc, phân tích và chia thành các nhóm kiểu mặt ngắn, trung bình, dài. Kết quả: trong các nguyên nhân gây sai lệch xương loại III, nguyên nhân do quá phát xương hàm dưới chiếm $55.72 \%$, tiếp đến là nguyên nhân do kém phát triển xương hàm trên và với $17.14 \%$ là do kết hợp kém phát triển xương hàm trên và quá phát xương hàm dưới. Trong số bệnh nhân tham gia nghiên cứu , 37 người có kiểu mă̆t trung bình, 19 bênh nhân có kiểu mặt ngắn và bệnh nhân có kiểu mặt dài là 14 người.

*Trường Đại học Y Hà Nội

Chịu trách nhiệm chính: Trần Thị Diệu Linh

Email: dieulinhrhm@gmail.com

Ngày nhận bài: 3.6.2021

Ngày phản biên khoa họ: 3.8.2021

Ngày duyệt bài: 11.8.2021

\section{Trần Thị Diệu Linh*, Quách Thị Thúy Lan*}

Các đặc điểm về chiều dài cành cao, chiều dài nền xương và chiều dài Co-Gn ở nhóm bênh nhân nam lớn hơn giá trị tương ứng ở nhóm nữ giới.

Tư khóa: xương hàm dưới, sai lệch xương loại III, phim sọ nghiêng, Trường Đại học Y Hà Nội.

\section{SUMMARY \\ THE CHARACTERISTICS OF THE MANDIBLE ON LATERAL TELETOLOGICAL CEPHALOMETRIC FILM IN PATIENTS WITH CLASS III MALOCCLUSION}

Class III malocclusion is considered a complex cranio-facial disorder, which may represent mandibular prognathism or maxillary retrognathism, or a combination of both. Understanding the characteristics of cranio-facial growth, especially mandibular structures in this group of patients will help doctors determine the timing and mechanics of treatment. The study aimed to describe the characteristics of the mandibule on Cephalometrics films in patients with class III malocclusion at the Institute of Odonto-Stomatology - Hanoi Medical University. Pretreatment lateral cephalometric radiographs of 70 patients with 18 years or older, with no history of trauma or craniofacial anomalies, were measured, analyzed and classified into short, average, and long faces. Results: in the different combinations between maxillomandibular relationships in the class III group, prognathic mandible is accounted for $55.72 \%$, followed by the retrognathic maxilla and the $17.14 \%$ is due to a combination of both. Among the 